\title{
ESCRITAS À FLOR DA TELA: FONTES DIGITAIS PARA A HISTÓRIA DA EDUCAÇÃO
}

Robson Fonseca Simões ${ }^{1}$

\begin{abstract}
O sgt Tavares faz parte da historia do CMRJ. [...] Apos, todos estarmos sentados, ordenou que colocassemos os sapatos, e que o ultimo a calçar seria punido, teria o nome e numero anotados ${ }^{2}$
\end{abstract}

Ele apontava o indicador para a direita, ainda com a cabeça virada para a esquerda, e gritava: VOCE, NOME E NUMERO ${ }^{3}$

Numa primeira tentativa de trazer para o debate as memórias da escola que transitam nas redes sociais do Orkut, procuro revisitar a obra épica de $\mathrm{CAMÕES}^{4}$, mais especificamente no momento glamoroso em que os heróis lusitanos, após as suas conquistas e batalhas, foram surpreendidos na ilha dos Amores, território prodigioso para novas conquistas; nesse sentido, traço uma possível intertextualidade, considerando as escritas memorialísticas nas redes sociais virtuais, territórios férteis para a História da Educação brasileira.

O trabalho com a memória pode nos ajudar a descrever alguns aspectos ligados à vida escolar por meio das situações diárias vividas pelos ex-alunos, como por exemplo, no exercício militar, ou em outras palavras, a ordem unida, trazendo possíveis novidades, numa revisita ao espaço geográfico e social escolar, mesmo observando uma escrita despojada de regras normativas linguísticas. Assim, se abrirmos com disposição as páginas das redes sociais virtuais, poderemos também nos surpreender com as memórias dos usuários encontradas nas comunidades do

\footnotetext{
${ }^{1}$ Professor da Universidade Federal de Rondônia/UNIR - fonsim2000@hotmail.com

${ }^{2}$ Escrita retirada do Fórum Quem se lembra do SGT Tavares?, da comunidade do Colégio Militar do Rio de Janeiro, postada pelo usuário Eduardo C. no dia 12/11/2005.

${ }^{3}$ Escrita retirada do Fórum Quem se lembra do SGT Tavares?, da comunidade do Colégio Militar do Rio de Janeiro, postada pelo usuário Roberto C. no dia 10/12/2005.

${ }^{4}$ CAMÕES, Luis de. Os Lusíadas. Rio de Janeiro: Ed. Klick, 1999.
} 
Orkut; nas tramas das histórias escolares, os "posts" digitais exibem os relatos dos ex-alunos, numa verdadeira exibição do eu.

Os depoimentos sobre o Sargento Tavares, na epígrafe deste texto, ainda que isentos de aplicações das regras de acentuação das palavras da língua portuguesa, apoiam-se, sobremaneira, nas atividades dos exercícios militares com os ex-alunos no pátio daquela instituição de ensino, como também iluminam os hábitos de vida militar, as formas de sociabilidade do militar instrutor com os exalunos e as práticas culturais desenvolvidas por aquela escola. As aulas de instrução militar, portanto, estão inscritas numa rede social em que os sujeitos constroem suas representações livres de moldes ou regras linguísticos, o que não compromete o relato postado.

As escritas virtuais nascem com uma vocação exibicionista para serem vistas e lidas por milhões de olhos alheios nas telas da rede mundial de computadores. Os estudos de VIÑAO (2000) indicam que as escritas virtuais podem ser um grande subsídio que marca a importância de fontes autobiográficas na escrita da História da Educação:

\footnotetext{
Um cambio radical en la nocion de privacidad. En una época en que lo íntimo es rentable o, al menos, pude serlo cuando se convierte em público, y en la que la privacidae virtual sustituye a la privacidad real - 0 esta última deviene virtual -, escribir diarios personales accessibles de un modo general a desconocidos- y conocidos- equivale, en el mundo de la nueva cultura escrita, al acto de mostrar, en la pantalla televisiva, los sentimentos y emociones más personales e íntimos. (VINÃO, 2000, p.14)
}

Como os usuários narram as suas histórias escolares? As escritas memorialísticas das comunidades escolares do Orkut, diferentemente de esgotarem todas as possibilidades de gêneros discursivos, ampliam a discussão sobre as tipologias textuais, mais especificamente, uma estrutura composicional do gênero discursivo internético, oferecendo como fortuna linguística, os depoimentos dos usuários, as suas memórias de um tempo de escola, que são produzidas por esses usuários nesse novo suporte textual.

Quais os possíveis significados e intenções que os usuários atribuem aos seus textos? Esta questão suscitada é reveladora de uma preocupação em 
reconhecer o grande desafio que se coloca em sofisticar o repertório das histórias dos sujeitos não representadas em outros tipos de documentos. Os cliques desses sujeitos desmancham as possíveis fronteiras que separavam os espaços públicos e privados, desafiando as velhas categorias, demandando novas interpretações, instigando-me a pensar que o registro dessas experiências possibilita ao sujeito "desnudar-se".

Mas quem são estes sujeitos nas comunidades escolares? Nasce, assim, uma discussão nesta comunidade escolar virtual; a questão da identidade do mundo virtual pode ser interpretada como uma verossimilhança literária, ou em outras palavras, as criações semânticas, sintáticas e estilísticas dos sujeitos são representadas a partir do universo da imaginação dos usuários.

O que é nome? O que significa nomear? Os estudos sobre os nomes e as suas respectivas escolhas realizados por Mignot (1993, p. 620) sugerem que: "Nomear implica designar, proferir, chamar, criar, instituir, eleger, escolher. A escolha de um nome é sempre um ato de arbítrio, liberdade, manipulação, dominação". Por outro lado, o nome marca também uma forma de classificação. Machado (2003, p.27), por sua vez, assinala: "O nome marca também um aspecto da subjetividade ou da posição social daquele que nomeia, e que é significado pelo nome que escolhe. Portanto, o nome é sempre significativo." Nesse sentido, podemos observar alguns nomes escolhidos pelos usuários da comunidade do Colégio Marista São José do Rio de Janeiro para um de seus professores, destacando os momentos importantes nas suas vidas escolares, como se observa a seguir.

Bio Molécula... Quem nao lembra desse grande professor? Vcs se lembram desse prof. de biologia? Todo mundo escolheu esse nome pra ele...Eu lembro dele dormindo durante a prova..saudades de vcs... ${ }^{5}$

Podes crer... Senhor Bio Molécula!! Nunca mais esqueci dele...Adorava aquele mestre... Bio Molécula era showwwww...

\footnotetext{
${ }^{5}$ Escrita retirada do Orkut em 09/03/2010, no Fórum Bio Molécula, da comunidade do Colégio Marista São José do Rio de Janeiro, postada pelo usuário Valente C. em 01/08/2004.

${ }^{6}$ Escrita retirada do Orkut em 09/03/2010, no Fórum Bio Molécula, da comunidade do Colégio Marista São José do Rio de Janeiro, postada pelo usuário Fabiano C. em 10/08/2004.
} 
Parece confirmar que o nome Bio Molécula foi escolhido pelos alunos para homenagear aquele professor de Biologia, do Colégio Marista São José do Rio de Janeiro, com um significado que vai além de uma metáfora, de uma metonímia, ou das próprias personificações dos elementos que compõem as especificidades das ciências da natureza.

Por sua vez, Machado (2003) procura examinar um dos grandes mistérios que assombram o leitor, em todas as épocas e sociedades: como funcionam os mecanismos das escolhas dos nomes nas narrativas? Machado (2003, p.27) explica: "o ponto de partida está diante de uma página em branco de um romance ou novela; as únicas palavras já preexistentes são os nomes dos personagens, tudo o mais poderá ser escolhido pelo autor [...]". Debruçando-se sobre as obras literárias de Guimarães Rosa, a autora examina de perto como os nomes desempenham um papel deflagrador e estruturador nas narrativas. Por sua vez, Houaiss (2003) entende que:

\begin{abstract}
essas transformações sígnicas (de significante e significado) se operam já por recursos paronímicos regulares da língua hipocorísticos, diminutivos, aumentativos, redobros, desdobros, indobros, dedobros -, já por recursos regulares da fala ou discurso - associações sônicas, fônicas, fonológicas, mórficas, morfemáticas, paradigmáticas ou sintagmáticas. [...] Cada nome próprio em Guimarães Rosa pode funcionar multivocamente, constituindo um centro de constelação sêmica palpitante de dinamismo e, mais, de adequação, quanto aos usos que de si mesma faz a personagem, os interlocutores, o próprio universo físico ou social que o envolve, inclusive o mítico, supersticioso, religioso, ideológico ou histórico. (Houaiss, 2003, p.10)
\end{abstract}

Há de se lembrar também, nesta reflexão, dos pseudônimos criados pelos poetas Tomás Antônio Gonzaga (Dirceu), Basílio da Gama (Termindo Sipílio) e Cláudio Manuel da Costa (Glauceste Satúrnio), ao final do século XVIII, no Brasil, ainda colônia portuguesa, para poderem destacar ecos de liberdade em suas escritas. Ao estudar os periódicos escolares ${ }^{7}$, Caruso (2005) comenta:

\footnotetext{
7 CARUSO, Andrea. "Traço de União como vitrine": educação feminina, ideário católico e práticas escolanovistas no periódico do colégio Jacobina. PRoPEd / UERJ. Dissertação de mestrado, 2006.
} 
No início do século $X X$, mais especificamente nas escritas da impressa quando havia uma função de proteger as autoras e suas famílias de críticas mal intencionadas, também é possível observar a continuidade na utilização de outros nomes para assinar artigos, que estava mais relacionada a uma lógica estética, pois as assinaturas com pseudônimos europeus, por exemplo, davam certo charme e elegância à escrita, já que tudo que vinha da Europa era considerado, principalmente pela elite daquela época, mais avançado e refinado. (CARUSO, 2005, p.24).

Os estudos de Rocha, O. (2003) permitem ver que os pseudônimos vão saindo de cena, quando a condição social da mulher vai mudando e dando lugar a um discurso socialmente aceito. Assim, infere-se que essas estratégias com designações de outros nomes para identificar um sujeito não são de exclusividade do universo virtual. Os autores estabeleceram e ainda descobrem novas estratégias de autoria, pensando sobretudo nas formas de relação com os seus interlocutores, preservando, assim, os seus anonimatos nos textos.

Nas janelas abertas dessas redes sociais virtuais, observam-se os nicknames. O espectro da representação provocado pelas tecnologias digitais desencadeou a presença verossímil de uma pessoa na rede, o hiper-eu, um alguém digital na comunidade escolar do Orkut, podendo não ser o usuário; são os nomes criados pelos sujeitos da internet, que por um motivo ou outro, não necessariamente representam as suas identidades reais. Estes nomes têm um valor discursivo por ser uma espécie de apelido com o qual o usuário deseja ser reconhecido. Com o seu nome real ou não, esses sujeitos convocam a desmesurada publicização do privado (VIÑAO, 2000), levando a exibição da intimidade (SIBILIA, 2008) e a celebração do tom confessional (BAUMAN, 2011) como forma de legitimar a performance da própria existência.

É possível refletir que essas estratégias com designações de outros nomes para identificar um sujeito não são utilizadas apenas na internet, não são de exclusividade do universo virtual. Quem sabe, um baile de máscaras, uma carnavalização na escrita da internet (BAKHTIN, 1979), na medida em que essa transposição do carnaval pode caracterizar-se por proceder a uma inversão do cotidiano, por corresponder à vida escolar que não está escrita ou narrada nos documentos oficiais encontrados na instituição. 
Como os usuários se apropriam dessas escritas nesses espaços virtuais nos quais são postadas as suas memórias escolares? A escrita, como representação de ideias ou palavras codificadas nos mais diversos suportes culturais, é parte integrante de uma realidade social; é possível entender que nesses ambientes linguísticos, os sujeitos criam sistemas, instrumentos, estruturas, para auxiliá-los na interação e no diálogo com o outro; nessa acepção, talvez, seja possível recorrer aos estudos de Castillo Gómez (2002) para compreendermos a história social da cultura escrita:

\begin{abstract}
la historia del lenguaje y de la cultura escrita no puede ser exclusivamente una historia de los sistemas de escritura, sino que debe interpretar el contenido y la modalidad de las diferentes prácticas de lo escrito. el valor y el uso que las distintas sociedades le han dado y le dan. Esto implica entender la escritura como una tecnología de razonamiento y comunicación social capaz de generar modos propios de pensar el mundo y construir la realidad, advirtiendo que esas potencialidades dependen de las condiciones de su posibilidad, de la distribución histórica de las capacidades de escribir y leer, de los discursos. (GÓMEZ, 2002, p. 116)
\end{abstract}

Por se tratar de um fenômeno social, considera-se que a língua precisa ser compreendida como inseparável do processo comunicativo, sendo despertada nessas relações pelo fato de que, através da linguagem, o ser humano tem acesso à cultura e ao conhecimento que o farão refletir na relação com o outro.

Como na interação face a face, a interação tela a tela requer dos usuários algumas habilidades que envolvam possíveis conhecimentos paralinguísticos e socioculturais; isso significa dizer que essa atividade comunicacional, assim como as demais, se apresenta ligada a uma vinculação situacional ${ }^{8}$; não pode a língua, nessa esfera específica da comunicação humana, ser separada do contexto em que se efetiva (MARCUSCHI, 1991). Nesse sentido, a linguagem pode ser entendida e produzida no e pelo contexto sociocultural. O scrap abaixo, encontrado na comunidade do Colégio de São Bento do Rio de Janeiro, pode nos ajudar a pensar essa reflexão.

\footnotetext{
${ }^{8}$ MARCUSCHI, Luis Antonio, Análise da conversação, São Paulo, Ática, 1991.
} 
Valew, galera. Istudei de 1969 a 1971. Como eu sinto falta da nossa turma... Eu lembo que tive várias participações no colégio. Como era feliz. Pra ficar mais fácil, era conhecido no col. como Marrinha. Tb fui um dos desafinados do coral e um dos piores jogadores de futebol do colégio ${ }^{9}$

Escrever, portanto, se constitui uma produção de memória, e, por conseguinte, um instrumento para rever o passado; a escrita, nessas comunidades escolares do Orkut, anuncia histórias do cotidiano escolar, de festas e comemorações oferecidas pela instituição de ensino, das emoções vividas pelos exalunos. Assim, estas postagens constituem partes fundamentais do tecido das lembranças dos sujeitos que não se intimidam em narrar nessas novas materialidades de escrita, que interessam à história da cultura escrita ${ }^{10}$, e que também unem os usuários das comunidades.

No que diz respeito à construção do objeto de pesquisa, a primeira etapa do trabalho foi a de constituir um corpus documental, no período de dezembro de 2009 a dezembro de 2010, acompanhando e gravando arquivos com os scraps dos usuários $^{11}$ das comunidades do Orkut de dez escolas ${ }^{12}$ no Rio de Janeiro, observando as escritas memorialísticas dos sujeitos relacionadas às suas histórias escolares. Em seguida, iniciaram-se os contatos com dez moderadores ${ }^{13}$, para que eu pudesse ter acesso às comunidades, enviando-lhes uma carta ${ }^{14}$ para

\footnotetext{
${ }^{9}$ Escrita retidada do Fórum Alunos dos anos 70, da comunidade do Colégio de São Bento do Rio de Janeiro, postada pelo usuário Maurício em 24/05/2005.

10 Esta abordagem vem sendo realizada pelo grupo liderado por António Castillo Gómez e Verônica Sierra Blas que lançou recentemente uma coletânea de estudos intitulada "Mis primeros pasos.Alfabetización, escuela y usos cotidianos de la escritura (siglos XIX y XX)"(2008). Para eles, a História da Cultura Escrita é o estudo da produção, difusão, uso e conservação dos objetos escritos; para isso busca alianças com quantos saberes, como os advindos da História da Educação escolarizada, que têm [...] como seu objeto o estudo da escrita em suas várias modalidades (p.19). Ver também: CASTILLO GÓMES, António / org. (2002).

${ }^{11}$ Optei em abreviar os sobrenomes dos sujeitos e esfumaçar as imagens gravadas nos arquivos para preservar a identidade dos usuários.

${ }^{12}$ Públicas, particulares e confessionais: Colégio Pedro II/Engenho Novo/RJ, Colégio Santo Inácio/RJ, Colégio Sion/RJ, Centro Federal de Educação Tecnológica do Rio de Janeiro, Instituto Superior de Educação/ RJ, Colégio Estadual Amaro Cavalcante/RJ, Colégio Militar/RJ, Colégio Marista São José/RJ, Colégio de São Bento/RJ, Instituto Abel/RJ.

${ }^{13}$ Usuários responsáveis pelas comunidades escolares do Orkut.

${ }^{14}$ Nessa carta encaminhada em 14/09/2010, eu me apresento aos moderadores das comunidades escolares como pesquisador do ProPEd, enfatizando o meu interesse pelas postagens naquelas
} 
aproximação; obtive o retorno de quatro moderadores das seguintes comunidades escolares: Colégio Militar do Rio de Janeiro, Colégio Marista São José do Rio de Janeiro, Colégio de São Bento do Rio de Janeiro e Instituto Abel do Rio de Janeiro; a escolha pelas três escolas centenárias, situadas na cidade do Rio de Janeiro, foi um critério de seleção para a pesquisa, uma vez que o Instituto Abel localiza-se em outra cidade do estado do Rio de Janeiro. Assim, retomei o contato via e-mail, solicitando-lhes uma possível resposta a algumas questões ${ }^{15}$ que foram inspiradas no questionário ${ }^{16}$ formulado por Alberca (2000). Após receber as respostas dos questionários dos moderadores, procurei chegar aos usuários, ex-alunos das escolas, procurando entrecruzar dados com os posts dessas comunidades escolares do Orkut.

As práticas das escritas memorialísticas dos usuários das comunidades das escolas no Orkut também oferecem outras possibilidades ao pesquisador, na medida em que algumas palavras ou expressões não são tão conhecidas ao serem representadas pelos usuários nessas redes sociais virtuais. Nas narrativas dos sujeitos, os usuários revisitam espaços, recordam histórias, acontecimentos que podem ser lembrados com apenas uma palavra.

Por meio das palavras dos usuários dessa comunidade escolar do Orkut, observam-se expressões: bibico, boina, aluno, quase militar, infantaria, que juntas compõem o cenário cotidiano de uma instituição militar. Por meio delas é possível conhecer aspectos do mundo militar e as possíveis vestimentas que são utilizadas

redes sociais do Orkut; terminei esse texto, deixando à disposição o meu endereço eletrônico, aguardando um possível contato daqueles sujeitos.

${ }_{15}$ Quando surgiu e qual(is) o(s) motivo(s) que o levou a ser um moderador na comunidade da sua escola no Orkut? Há algum estatuto para ser moderador? Qual o papel do moderador nesta comunidade virtual? Você usa algum mecanismo para verificar de fato que um novo usuário realmente teve algum vínculo com a sua escola? Qual o mecanismo? Quais as regras utilizadas para se permitir o acesso de um(a) novo(a) usuário(a)? Você armazena todas as escritas dos usuários? Caso afirmativo, quais os critérios que você utiliza para armazená-las? Com que frequência você acessa a sua comunidade? Por quê? Na sua opinião, qual(is) o(s) motivo(s) que estimula(m) o usuário a participar desta comunidade? Quais os Fóruns que você criou com mais postagens? Você poderia identificar qual é o tema mais recorrente nesta rede de sociabilidade virtual? Você já promoveu algum encontro presencial com os usuários da comunidade? Tem vontade de fazê-lo? Alguma vez você já leu algo postado por algum usuário, do qual você não tenha gostado? O que fez? Assinale quais os tipos de textos que você mais percebe circular na comunidade: poemas, canções, crônicas, recordações, relatos, pensamentos, artigos, correspondências, fotografias, imagens.

${ }^{16}$ A pesquisa desse pesquisador espanhol, aplicada em 1995 e 1996, na cidade de Málaga, aos alunos universitários e do ensino médio, num total de 702 sujeitos, entre homens e mulheres, procurava entender, se mesmo num mundo dominado pela cultura audiovisual, havia espaço para a cultura escrita de um diário. 
pelo corpo de alunos naquela instituição de ensino. À medida que despertam lembranças, as palavras ditas pelos ex-alunos personificam uma educação militar vivida pelos usuários. Nessa acepção, os uniformes, a rotina, a vida cotidiana escolar, servem como testemunhos de um tempo escolar.

De história em história, vai-se compondo o passado dos ex-alunos e, por entre as memórias, o despojamento dos costumes, valores, práticas escolares. Os estudos de Nicolaci da Costa (2006) mostram que o computador e a internet se metamorfosearam em instrumentos tecnológicos multifuncionais, permitindo os sujeitos serem percebidos coletivamente, conectando, portanto, o outro numa espécie de telepresença ${ }^{17}$ em rede, numa experiência cotidiana na qual apenas alguns elementos (texto, imagem, som) em detrimento de outros (texturas, odores, sabores) personificam-se em espectros pelos quais os usuários se manifestam, abrindo espaço para reapresentação dos cenários do passado nas comunidades das escolas no Orkut.

Se mudou o suporte da escrita de um diário (do papel para a tela do computador), contudo vários objetivos e funções permanecem; segundo ALBERCA (2000) a escrita e os motivos que levam alguém a escrever um diário envolvem funções terapêuticas - para desabafar, contar os desassossegos da alma; funções éticas - para guardar a memória dos momentos exemplares que se referem à boa conduta humana; e funções estéticas - para conservar o diário como ato de escrita, como expressão da cultura gráfica de seu tempo, pois a prática diarista liga-se à necessidade de introspecção, de comunicação, para contar experiências, para relacionar-se com um interlocutor ideal. Aquele autor espanhol explica que as escritas em diários podem ser vistas como um exercício do cidadão moderno sair do isolamento;

De manera general pero cierta el diário se relaciona com la soledad, y lo atestiguan la mayoría de los testimonios, que lo consideran como um ejercicio y um refugio para combatirla, para salir del aislamento $y$, finalmente, para superar la falta de comunicacíon. [...]Pero no se deve olvidar que para ecribir um diário, em el gesto y em el fondo, se precisa también recogimiento

\footnotetext{
${ }^{17}$ LOBO, Luiza. Segredos públicos: os blogs de mulheres no Brasil. Rio de Janeiro: Rocco, 2007.
} 
y aislamiento, que se necesita y se debe optar em muchas ocasiones por estar solo. (ALBERCA, 2000, p. 35)

Vivendo-se num impacto de revoluções tecnológicas das mais variadas ordens documentais e de uma enorme ampliação de memórias históricas, não é possível permanecer com olhos vendados para o universo virtual. Se os diários de viagem, correspondências, relatórios de diretores, de professores, memoriais, desenhos e fotografias aguardam o olhar atento dos pesquisadores, as páginas das comunidades escolares do Orkut devem fazer parte, também, do repertório de textos que contribuem para a investigação de outras escritas memorialísticas.

Portanto, as escritas memorialísticas da comunidade do Orkut cumprem o seu papel, abrindo uma via de acesso ao terreno das memórias autobiográficas, desvelando histórias escolares encenadas no passado e presentificadas nessa rede social virtual. Os ex-alunos compartilham experiências, sentimentos e saberes, borrando fronteiras entre o público e o privado; nesse sentido, percebe-se que essas escritas autobiográficas nas comunidades escolares do Orkut também constroem esses sujeitos no suporte digital. É possível nos surpreendermos nesses Fóruns virtuais, mediados pelos moderadores, da mesma forma que possamos nos admirar com os relatos nos cadernos, nas agendas, nos diários dos sujeitos com as suas histórias escolares.

Talvez ali, numa direção adversa dos possíveis registros oficiais das instituições de ensino, estejam registradas outras histórias das culturas, histórias da vida escolar dos ex-alunos. Se essas redes sociais virtuais também são feitas de produções e tensões que nos permitem elaborar e partilhar sentidos, talvez ali mesmo, na fluidez e na intensidade dos fluxos, nos borramentos das fronteiras virtuais, seja possível observar imaginários e histórias, construindo em trânsito e em processo, quem sabe, os relatos de memórias que não puderam ser registrados em outras materialidades.

Resta o desafio de não deixarem desmoroná-los, como os castelos de areia são desmoronados com os ventos do deserto, mas procurar deixar as memórias se fortalecerem, mesmo no universo efêmero, no imperativo da conexão, sob os olhares dos mediadores nas comunidades escolares do Orkut. Talvez assim, 
possam existir novos refúgios para o eu. Mas quem disse que isso é o fim? Se a efemeridade habita os suportes virtuais, certamente, amanhã outras redes sociais estarão franqueadas à visita dos pesquisadores que desejarem examinar outras histórias de um tempo escolar.

\section{REFERÊNCIAS}

ALBERCA, Manuel. La escritura invisible: testimonios sobre el diário íntimo. Madrid: Sendoa, 2000.

AYMARD, Maurice. Amizade e convivialidade. In: CHARTIER, Roger. História da vida privada, 3: da Renascença aos Séculos das Luzes. São Paulo, Companhia das Letras, 2009.

BAKHTIN, Mikhail. Problemas da poética de Dostoievski. São Paulo: Forense universitária, 1979.

BAUMAN, Zygmun. A Face humana da Sociologia. In: Estado de São Paulo online, 2011. Disponível em <http://www.estadao.com.br/noticias/a-face-humana-dasociologia> Acesso em 30/09/2012.

CAMÕES, Luis de. Os Lusíadas. Rio de Janeiro: Ed. Klick, 1999.

CARUSO, Andrea. Traço de União como vitrine: educação feminina, ideário católico e práticas escolanovistas no periódico do colégio Jacobina. Dissertação de mestrado. PRoPEd / UERJ. 2006.

CASTILLO GÓMEZ, Antônio (org.). História de La cultura escrita. Madrid: Trea, 2002.

CERTEAU, Michel de. A escrita da história. Rio de Janeiro: Forense Universitária, 1982.

CHARTIER, Roger. A aventura do livro: do leitor ao navegador. São Paulo: Fundação Editora da Unesp, 2002.

HOUAISS, Antônio. Prefácio que deveria ser posfácio. In: MACHADO, Ana Maria. Recado do nome: Leitura de Guimarães Rosa à luz do Nome de seus personagens. Rio de Janeiro: Nova Fronteira, 2003. pp. 7-22.

LEJEUNE, Philippe. O pacto autobiográfico: de Rousseau à internet. Belo Horizonte: Ed. UFMG, 2009.

MACHADO, Ana Maria. Recado do nome: Leitura de Guimarães Rosa à luz do Nome de seus personagens. Rio de Janeiro: Nova Fronteira, 2003.

MARCUSCHI, Luís Antônio. Análise da conversação. São Paulo: Ática, 1991. 
MIGNOT, Ana Chrystina Venâncio. Decifrando o recado do nome: uma escola em busca de uma identidade pedagógica. In: Revista Brasileira de Estudos Pedagógicos, 1993, v. 74, pp. 619-638.

NICOLACI-DA-COSTA, Ana Maria (org). Cabeças Digitais: O cotidiano na era da informação. Rio de Janeiro: Ed.Pucrio, 2006.

RICOUER, Paul. Tempo e narrativa. São Paulo: Papirus, 1994.

ROCHA, Olívia Candeia Lima. Escritoras piauienses: pseudônimos, flores e espinhos. Mafuá-Revista de Literatura em Meio Digital, dez. 2003. Disponível em: <http://www.mafua.ufsc.br/oliviacandeia.html> Acesso em jan. 2012.

SIBILIA, Paula. O show do eu: a intimidade como espetáculo. Rio de Janeiro: Nova Fronteira, 2008.

SOUZA, Elizeu Clementino. O conhecimento de si: estágios e narrativas de formação de professores. Salvador: Uneb, 2007.

VIÑAO, Antonio. Las autobiografias, memorias y diarios como fuente historicoeducativa: tipologia y usos. In: TEIAS: Revista da Faculdade de Educação, UERJ. Rio de janeiro, n.1, jun. p. 82-97, 2000. 